Notes and miscellanea

\section{Angiosarcoma of liver and spleen in a scrap metal merchant}

Angiosarcoma of the liver is a rare tumour that may be used as a marker tumour to identify human carcinogens. Thoratrast, inorganic arsenic, copper, and vinyl chloride have been implicated as carcinogens producing this tumour. ${ }^{2}$

\section{Case report}

A 56-year-old self-employed scrap metal merchant collapsed and died at home nine days after presenting with a two-week history of lethargy, weight loss, indigestion, and abdominal pain. He had a history of indigestion and had tended to drink excessively. On initial examination he was obviously unwell and clinically anaemic. His liver was enlarged. Investigations showed $\mathrm{Hb} 9 \mathrm{~g} / \mathrm{dl}$, ESR $30 \mathrm{~mm}$ in first hour, blood urea and serum electrolyte concentrations within normal limits, serum alkaline phosphatase 291 $\mathrm{IU} / \mathrm{l}$. He died the day after a barium meal examination.

Postmortem examination showed that death was due to a massive intraperitoneal haemorrhage from a multinodular haemorrhagic tumour of the liver (total weight of liver $2200 \mathrm{~g})$. The spleen $(1500 \mathrm{~g})$ was greatly enlarged and had a firm white fleshy cut surface (fig). Histological examination of the tumour in the liver and spleen showed the appearances of an angiosarcoma. There were no other tumour deposits present and no other significant findings.

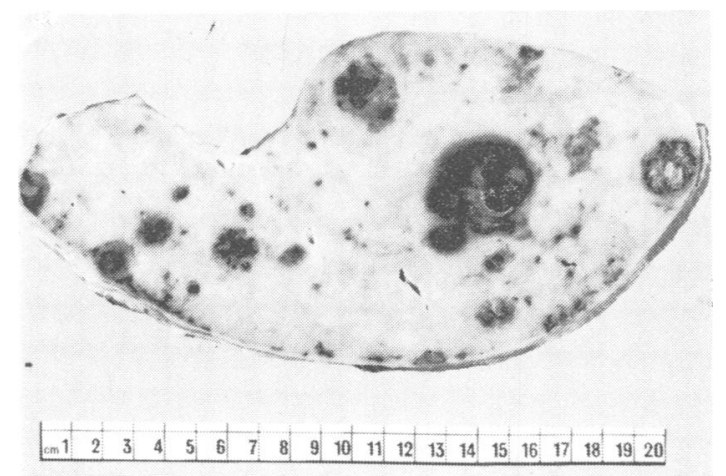

Fig Spleen replaced by tumour $\times 112$ magnification.
He had not smoked for 20 years but had consumed about four pints of beer and an eighth of a bottle of whisky daily before his death, and had probably consumed more in earlier years. There was no history of exposure to thoratrast or arsenical medications. He had been a scrap metal merchant all his working life and had been recovering copper from plasticcoated cable and a small amount of rubber-coated cable for the past 15 years. This entailed burning about $500 \mathrm{~kg}$ of the cable at weekly to monthly intervals. To separate the copper completely from the plastic it was necessary to rake the burning cable constantly for two to three hours. He wore no protective clothing or mask despite the acrid smoke. The yard in which he had worked for the past 15 years was next to a PVC fabricating factory.

\section{Discussion}

The Employment Medical Advisory Service has reported an increased risk of angiosarcoma of the liver in the electrical and plastics fabrication industries. ${ }^{1}$ Other studies suggest that alcohol may act as a co-carcinogen or promoting agent. ${ }^{3}$ Studies on the combustion effects of PVC have shown that the main constituents released are hydrochloric acid, carbon monoxide, carbon dioxide, and traces of benzene. Small quantities of vinyl chloride monomer have also been detected. ${ }^{4}$ Other studies have shown release of greater quantities of vinyl chloride from plastics commonly used for wire insulations. This may be due to the combustion of the plasticisers used in the formulation of these plastics. ${ }^{5}$ Arsenic may be inhaled during the burning of scrap metal. In this case, therefore, there was probably a low-level exposure to several carcinogens including vinyl chloride, copper, and arsenic with alcohol acting as a possible cocarcinogen. "Burning off" to recover copper has been widely practised by scrap metal merchants and some electrical contractors over the past 15-20 years, using little or no protective measures. The latent period between exposure to thoratrast and vinyl chloride and diagnosis of angiosarcoma of the liver is 12-29 years, and further cases may therefore still present in the scrap metal industry. It would seem advisable for workers burning off scrap to use suitable protective measures until the carcinogenic effect of this practice is better established.

We thank Professor P J Scheuer for his opinion on sections from the tumour.

$$
\begin{array}{r}
\text { F J FAWCETT } \\
\text { District Hospital, } \\
\text { Peterborough PE3 6DA } \\
\text { PHILlIPA EASTERBROOK } \\
\text { Clinical School, University of Cambridge, } \\
\text { Addenbrooke's Hospital, Cambridge CB2 } 2 Q Q \\
\text { G SMERDON } \\
\text { St Ives, Cambs PE17 4RA }
\end{array}
$$




\section{References}

${ }^{1}$ Baxter PJ, Anthony PP, MacSween RNM, Scheuer PJ. Angiosarcoma of the liver: annual occurrence and aetiology in Great Britain. Br J Ind Med 1980;37:213-221.

${ }^{2}$ Anonymous. Angiosarcoma of the liver: a growing problem? $\mathrm{Br}$ Med J 1981;282:504-5.
${ }^{3}$ Radite MJ, Stemmer KL, Brown PG, Larson E, Bingham E. Effect of ethanol and vinyl chloride on the induction of liver tumours: Environ Health Perspec 1977;21:153-5.

${ }^{4}$ Woolley WD. Decomposition products of PVC for studies of fires. British Polymer Journal 1971;3:186-93.

${ }^{5}$ Boettner EA, Ball G, Weiss B. Analysis of the volatile combustion products of vinyl plastics. Journal of Applied Polymer Science 1969;13:377-91. 